\title{
Cultural Dimensions of Career Decision-Making Difficulties
}

\author{
Wei-Cheng J. Mau
}

\begin{abstract}
This study investigated cultural dimensions of career decision-making difficulties using the Career Decision-Making Difficulties Questionnaire. Career decision-making difficulties were compared among White, African, Hispanic, and Asian American high school and university students at U.S. schools. Results indicated Asian American students perceived significantly more difficulties in career decision making than other groups, whereas White American students perceived the fewest difficulties. Asian American students reported more difficulties than White and Hispanic American students before the process and more difficulties than White and African American students during the process. Findings are discussed based on perspectives of cultural differences.
\end{abstract}

Career decision-making difficulty is emerging as an important construct in framing and understanding factors contributing to the career development of adolescents and young adults. Career decision-making difficulty has been linked to several critical career behaviors such as career indecision (Mau, 2001; Osipow \& Gati, 1998) and career decision-making self-efficacy (Gati, Osipow, Krausz, \& Saka, 2000). Just as it is important to understand what constitutes "ideal" career decision-making behaviors and attitudes, it is also important to understand the characteristics of "problematic" decision-making attitudes and behaviors that may lead to difficulties in career development.

Gati, Krausz, and Osipow (1996) classified career decision-making difficulties into three major clusters: (a) lack of readiness, which occurs before the decision-making process; (b) lack of information, which occurs during the decision-making process; and (c) inconsistent information, which also occurs during the decision-making process. These clusters are, in turn, subdivided. The first cluster, lack of readiness, includes three categories of difficulties: (a) lack of motivation to engage in the career decisionmaking process; (b) general indecisiveness concerning all types of decisions; and (c) dysfunctional beliefs, including irrational expectations. The second cluster, lack of information, includes four categories of difficulties:(a) lack of knowledge about the steps involved in the process, (b) lack of information about self, (c) lack of information about various career alternatives, and (d) lack of information about ways of obtaining additional information. The third cluster of difficulties, in-consistent information, involves (a) unreliable information, (b) internal conflicts, and (c) external conflicts. A total ofl0 categories thus constitute the taxonomy of career decision-making difficulties.

Researchers examining the constructs and validity of this taxonomy have found empirical support in a variety of populations, such as clients versus nonclients (Gati et al., 2000), people taking Internetbased versus paper-and-pencil career assessments (Gari \& Saka, 2001 ), cross-national comparisons (Gati et al., 1996; Mau, 2001), and high school (Gati \& Saka, 2001; Leung \& Hou, 2002) and university students (Osipow \& Gati, 1998). Although the validity of the career decision-making difficulty taxonomy has received wide support, its cultural implications and relevancy remain relatively unexamined.

It is well documented that cultural-contextual factors have a strong influence on individuals' career behaviors and outcomes. Blustein and Ellis (2000) argued that one of the challenges for career assessment in the 21 st century is the need to affirm cultural diversity. Increasing globalization and cultural diversity in the workforce necessitate that career assessment be relevant for all cultural groups (Fouad \& Zao, 2000). Reviews of career assessment tools suggest that very little has been done to examine applicability of career assessment to cultural minorities (Leong \& Hartung, 2000; Leong \& Leung, 1994). Leong and Hartung (2000) have indicated that studies focusing on cross-cultural career assessment have 
tended to focus on the cultural validity of existing instruments, which have been based predominantly on Western models of test construction.

Perception of career-related barriers and decision-making difficulties plays a significant role in the career development of women and ethnic minorities (Lent, Brown, \& Hackett, 1994). Studies have shown that women and ethnic minorities perceived more career-related barriers than did White American men (Luzzo \& McWhirter, 2001). In a cross-national study, Mau (2001) found that Taiwanese college students perceived more career decision-making difficulties than did American college students. He also found that the clusters of difficulty have different effects on career indecision depending on students' nationalities. This initial finding prompted further investigation of the perceptions of career decision-making difficulties among different racial and ethnic groups in the United States.

Conceptualization of the studies reported here is based on the dimension of individualismcollectivism widely used as a major dimension in examining cultural differences. At a psychological level, collectivism can be defined in terms of a person's consideration of the implications of his or her own decisions and actions for other people, the sharing of resources and outcomes of others' behaviors, susceptibility to social influence, and feelings of involvement in others' lives (Hui \& Triandis, 1986 ). As a result, collectivists have strong needs for affiliation, abasement, and nurturance. Individualists, on the other hand, have strong needs for autonomy and deference (Hui \& Villareal, 1989). Studies (e.g., Bellah, Madsen, Sullivan, Swidler, \& Tipton, 1985; Hofstede, 1980) have indicated that individuals in the United States and other Western countries score high in individualism, whereas those from Africa, Asia, and Latin America score high in collectivism. Minority groups in the United States (i.e., Hispanics, African Americans, and Asian Americans) have long been believed to be more group oriented compared with European Americans. Individuals from these minority groups may place more emphasis on familial aspirations and group decisions over their own. However, it is also expected that the younger generations of these minority groups may experience more decision conflicts as they attempt to assimilate into the majority culture and, at the same time, sort out their own cultural identity.

The aim of this research was to characterize and compare the different types of career decisionmaking difficulties faced by students of different racial and ethnic backgrounds who were about to make the transition from school to work. The difference between high school students and college students was also examined. The taxonomy of difficulties proposed by Gati et al. (1996) was used in this study as a general theoretical model for analysis of the differences. This study attempted to address the following questions: (a) Do ethnic minority students perceive more difficulties than White students in making career decisions and (b) Do the difficulties differ as a function of the decision process as well as its content? On the basis of previous findings comparing Taiwanese students and primarily White American students (Mau, 2000, 2001; Mau \& Jepsen, 1990), we predicted that Asian American students would perceive greater difficulties than White American students. We hypothesized that people of an individualistic culture would be less likely to report career decision-making difficulties than people of a collective culture. Considering the cultural difference regarding individualism and collectivism, it was also predicted that Asian American students would be more likely to report external-internal conflicts than other racial and ethnic groups.

Data were collected from two separate samples: high school and university student populations. The two populations selected for this study provided a good spectrum of career decision-making behaviors ranging from adolescence to adulthood. The high school sample described in Study 1 consisted of adolescents who were likely to be in the exploration stage. The university sample described in Study 2 comprised young adults who tended to be more decided in their career directions. Both populations were facing a transition point in which they had to make career decisions in the near future. According to developmental theories, the transition from adolescence to adulthood is crucial. 


\section{Study 1 \\ Method}

Participants. Three hundred and sixty-one high school students (158 boys and 203 girls) at two public schools with high proportions of minority students were selected to participate in the study. Ages ranged from 13 to 20 years $(M=15.9, S D=1.3)$, with 114 freshmen, 67 sophomores, 101 juniors, 76 seniors, and 3 did not respond. The racial-ethnic composition was 162 White, 59 African, 45 Hispanic, and 14 Asian Americans, and 81 who fell into other categories (25 Native Americans, 8 exchange students, and 48 who did not report ethnicity).

Instrument. The Career Decision-Making Difficulty Questionnaire School (CDDQ-HS; Gari \& Saka, 2001 ) is a newer version adapted from the original 44-item questionnaire (Gati et al., 1996) to suit the high school population. The CDDQ-HS includes 35 items, each corresponding to a specific difficulty area in Gati et al.'s (1996) taxonomy. The items are rated on a 7-point Likert scale from 1 (does not describe me at all) to 7 (describes me well). The coefficient alpha based on the 361 high school students who participated in this study is .91. Subscale coefficient alphas are .60 (Lack of Readiness), .91 (Lack of Information), and .83 (Inconsistent Information).

\section{Analyses}

First, the 10 scale scores, the three major categories scores, and the overall difficulty scores were computed for each individual participant. Because of unequal numbers of questions in each category, mean scores were computed as units of analysis. Second, the coefficient alpha reliability scores were estimated for each racial-ethnic group. Third, an analysis of variance (ANOVA) was conducted to examine overall difficulties in career decision making among racial-ethnic groups. Finally, a multivariate analysis of variance (MANOVA) was conducted to examine the differences among racial-ethnic groups in specific categories.

\section{Results}

Table 1 presents the means, standard deviations, and the coefficient alpha reliabilities of the career decision-making difficulty scales by race-ethnicity based on high school students. As shown in Table 1 , the alpha coefficients estimated for the 34-item CDDQ-HS ranged from .88 for African American students to .91 for White and Hispanic American students. The lowest internal consistency was observed in the Lack of Readiness scale estimated for African American students $(a=.45)$, whereas the highest internal consistency was observed for Asian American students $(a=.73)$. The alpha reliability coefficients estimated for Lack of Information and Inconsistent Information scales are moderately high for all racialethnic groups (from .77 to .91).

A one-way ANOVA was used to examine the overall difficulties in career decision making as a function of race-ethnicity. A significant difference was found as a function of race-ethnicity, $F(3,276)=$ 3.30, $p=.021$. Asian American students $(M=4.8, S D=1.2)$ reported significantly greater difficulties than White American students $(M=3.9, S D=1.2)$, African American students $(M=4.1, S D=1.2)$, and Hispanic American students ( $M=4.1, S D=1.2$ ). A MANOVA was conducted to examine differences in specific areas. Results showed significant racial-ethnic differences in career decision-making difficulties, $F(9,662)=2.52$, $p=.008$. Subsequent analysis indicated significant differences in Lack of Readiness, $F(3,274)=4.34, p=$ .005 , and Lack of Information, $F(3,274)=3.53, p=.015$. For difficulties arising before the decision-making process, Asian American students $(M=4.8, S D=1.2)$ scored higher in Lack of Readiness than White American students $(M=3.9, S D=1.1)$ and Hispanic American students $(M=4.0, S D=1.2)$. For difficulties occurring during the decision-making process, Asian American students $(M=4.9, S D=1.6)$ scored higher on Lack of Information than White American students $(M=3.7, S D=1.6)$. Asian American students $(M=$ $4.3, S D=1.6)$ also scored higher on Inconsistent Information than White American students $(M=3.5, S D=$ 1.4) and African American students ( $M=3.5, S D=1.4)$. 
TABLE 1

\section{Means and Standard Deviations for Career Decision-Making Difficulties by Race-Ethnicity for High School Students}

$(n=277)$

\begin{tabular}{|c|c|c|c|c|c|c|c|c|c|c|c|c|}
\hline \multirow[b]{2}{*}{ Variable } & \multicolumn{3}{|c|}{ White American } & \multicolumn{3}{|c|}{ African American } & \multicolumn{3}{|c|}{ Hispanic American } & \multicolumn{3}{|c|}{ Asian American } \\
\hline & Af & $S D$ & $\mathrm{a}$ & Af & SD & a & Af & SD & $\mathrm{a}$ & Af & $S D$ & $\mathrm{a}$ \\
\hline Motivation & 3.1 & 1.6 & .54 & 2.9 & 1.7 & .59 & 3.0 & 1.6 & .62 & 3.5 & 2.1 & .77 \\
\hline Indecisiveness & 4.3 & 1.8 & .58 & 4.9 & 1.9 & .47 & 4.7 & 1.8 & .69 & 5.9 & 1.1 & .17 \\
\hline About the process & 3.8 & 1.7 & .80 & 4.1 & 3.1 & .83 & 4.4 & 2.0 & .87 & 5.1 & 1.6 & .83 \\
\hline About the self & 3.6 & 1.8 & .79 & 3.6 & 2.0 & .76 & 3.9 & 1.9 & .75 & 4.5 & 2.0 & .84 \\
\hline About the alternatives & 4.2 & 2.0 & .8 & 4.7 & 2.1 & .71 & 5.0 & 2.1 & .79 & 5.8 & 1.6 & .79 \\
\hline About obtaining information & 3.2 & 1.9 & .75 & $\begin{array}{l}3 . \\
5\end{array}$ & 1.9 & .68 & 3.8 & 1.8 & .52 & 4.7 & 2.3 & .82 \\
\hline External conflicts & 3.0 & 1.9 & .80 & 2.9 & 1.6 & .24 & 3.0 & 2.0 & .64 & 3.8 & 2.3 & .51 \\
\hline Overall Difficulties & 3.9 & 1.2 & .91 & 4.1 & 1.2 & .88 & 4.1 & 1.2 & .91 & 4.8 & 1.2 & .89 \\
\hline
\end{tabular}

\section{Study 2}

Method

Participants. Five hundred thirteen college students (198 men, 310 women, and 5 who did not report gender) at an urban university in the midwestern United States participated in this study. Ages ranged from 15 to 54 years ( $M=22.0, S D=6.7$ ), with 296 freshmen, 118 sophomores, 49 juniors, 42 seniors, and 3 unknown. The racial-ethnic composition was 381 White, 37 African, 24 Hispanic, and 30 Asian Americans, and 41 who fell into other categories (5 Native Americans, 12 international students, and 24 who did not report ethnicity).

Instrument. The Career Decision-Making Difficulty Questionnaire (CDDQ; Gati et al., 1996) includes 44 items, each corresponding to a specific difficulty area in Gati et al. 's ( 1996) taxonomy. The items are rated on a 9-point Likert scale from 1 (does not describe me at all) to 9 (describes me well). Gati et al. (1996) reported that the median Cronbach alphas of the 10 subscale scores were .78 and .77 , for the Israeli and American samples, respectively. They also reported test-retest reliabilities (2-day intervals) of $.67, .74, .72$, and .80 for the three major categories (Lack of Readiness, Lack of Information, and Inconsistent Information) and the overall scale, respectively.

\section{Results}

Table 2 presents the means, standard deviations, and the coefficient alpha reliabilities of the career decision-making difficulty scales by race-ethnicity based on university students. As can be seen in Table 2, the alpha coefficients estimated for the 44-item CDDQ ranged from .96 for African American and Asian American students to .98 for White and Hispanic American students. The alpha reliabilities estimated for Lack of Information and Inconsistent Information were high (above .90) except for the Lack 
of Readiness scale. Hispanic American students had the lowest internal consistency estimated for the Lack of Readiness scale $(a=.48)$.

A one-way ANOVA was used to examine the overall difficulties in career decision making as a function of race-ethnicity. A significant difference was found as a function of race-ethnicity, $F(3,468)=$ 3.75, $p=.011$. Asian American students $(M=4.0, S D=1.5)$ reported significantly greater difficulties than White American students $(M=3.2, S D=1.4)$, African American students $(M=2.9, S D=1.5)$, and Hispanic American students $(M=3.0, S D=1.5)$. To examine racial-ethnic differences in specific difficulty areas, a MANOVA was conducted. Results of the MANOVA show significant differences in career decision-making difficulties as a function of race-ethnicity, $F(9,1134)=2.25, p=.017$. Subsequent analyses indicate significant racial-ethnic differences in Lack of Readiness, $F(3,468)=2.73, p=.043$, and Inconsistent Information, $F(3,468)=4.98, p=.002$. For difficulties occurring before the decision-making process (lack of readiness), Asian American students $(M=4.4, S D=1.4$ ) reported more difficulties than Hispanic American students $(M=3.7, S D=1.0)$. For difficulties occurring during the decision-making process, Asian American students reported more difficulties in Lack of Information than African American students ( $M=$ 2.8, $\mathrm{SD}=1.8)$. Asian American students $(M=3.6, S D=1.7)$ also scored higher in Inconsistent Information than African American ( $M=2.3, S D=1.5)$, Hispanic American $(M=2.5, S D=1.4)$, and White American ( $M$ $=2.6, \mathrm{SD}=1.5$ ) students.

TABLE 2

\section{Means and Standard Deviations for Career Decision-Making Difficulties by Race-Ethnicity for University Students}

$(n=472)$

\begin{tabular}{|c|c|c|c|c|c|c|c|c|c|c|c|c|}
\hline \multirow[b]{2}{*}{ Variable } & \multicolumn{3}{|c|}{ White American } & \multicolumn{2}{|c|}{ African American } & \multicolumn{3}{|c|}{ Hispanic American } & \multicolumn{2}{|c|}{ Asian American } & \multirow[b]{2}{*}{$S D$} & \multirow[b]{2}{*}{$a$} \\
\hline & $M$ & $S D$ & $a$ & $M$ & $S D$ & $a$ & $M$ & $S D$ & $a$ & $M$ & & \\
\hline Lack of Readiness & 3.8 & 1.1 & .63 & 4.0 & 1.5 & .79 & 3.7 & 1.0 & .48 & 4.4 & 1.4 & .73 \\
\hline Motivation & 2.7 & 1.6 & .58 & 2.7 & 1.8 & .59 & 2.2 & 1.6 & .73 & 3.1 & 2.0 & .72 \\
\hline Indecisiveness & 4.1 & 1.8 & .67 & 4.3 & 1.8 & .71 & 4.0 & 1.5 & .34 & 5.0 & 1.6 & .56 \\
\hline Dysfunctional beliefs & 4.7 & 1.7 & .39 & 4.9 & 2.2 & .63 & 4.9 & 1.7 & .37 & 5.2 & 2.0 & .63 \\
\hline Lack of Information & 3.2 & 1.9 & .95 & 2.8 & 1.8 & .97 & 3.0 & 2.2 & .98 & 4.1 & 2.0 & .96 \\
\hline About the process & 3.4 & 2.3 & .90 & 3.4 & 2.3 & .92 & 3.4 & 2.5 & .93 & 4.3 & 2.3 & .92 \\
\hline About the self & 3.3 & 1.9 & .93 & 2.5 & 1.8 & .95 & 2.9 & 2.4 & .96 & 3.7 & 1.9 & .90 \\
\hline About the alternatives & 3.4 & 2.3 & .90 & 2.7 & 1.9 & .91 & 2.8 & 2.1 & .88 & 4.3 & 2.3 & .89 \\
\hline About obtaining information & 3.0 & 2.1 & .76 & 2.5 & 1.9 & .80 & 3.1 & 2.6 & .94 & 4.0 & 2.2 & .77 \\
\hline Inconsistent Information & 2.6 & 1.5 & .92 & 2.3 & 1.5 & .95 & 2.5 & 1.4 & .90 & 3.6 & 1.7 & .91 \\
\hline Unreliable information & 2.8 & 1.8 & .87 & 2.5 & 1.9 & .94 & 3.1 & 2.3 & .90 & 3.7 & 1.8 & .77 \\
\hline Internal conflicts & 3.0 & 1.6 & .81 & 2.6 & 1.7 & .88 & 2.7 & 1.4 & .66 & 3.8 & 1.7 & .80 \\
\hline External conflicts & 2.1 & 1.6 & .86 & 2.0 & 1.4 & .79 & 1.6 & 1.3 & .86 & 3.4 & 2.2 & .79 \\
\hline Overall Difficulties & 3.2 & 1.4 & .98 & 2.9 & 1.5 & .96 & 3.0 & 1.5 & .97 & 4.0 & 1.5 & .96 \\
\hline
\end{tabular}




\section{Discussion}

The present study investigated differences in career decision-making difficulties with respect to race-ethnicity and the decision-making process. Data were drawn from two separate samples: high school and university student populations. Gait et al.'s (1996) career decision-making difficulty taxonomy was used to examine the differences.

As expected, findings from Study 1 showed that Asian American high school students reported more difficulties in all areas of career decision making than White American high school students. Cultural values have been identified as important variables in career decision making (Brown, 2003). The culture that is individual-oriented is more conducive to fostering independent, rational approaches to career decision making; hence, individuals from this culture may be less likely to report difficulties than students from a collective-oriented culture. Similarly, students from a culture in which an individual's aspirations are less emphasized than family aspirations may report more difficulties in those questions focusing on individual needs and aspirations (Mau, 2000, 2001). Unlike White American students, who tend to make their own career decisions, Asian American students may make career decisions that conform to familial and societal expectations.

In Study 2, Asian American university students also reported greater difficulties than African American and Hispanic American university students. Perhaps the university environment has acculturated African American and Hispanic American students to behave more like White American students in some aspects of their approaches to career decision making. Hispanic and African American students may have adopted White culture in order to succeed on predominantly White campuses. Further studies to clarify this hypothesis are warranted. Nevertheless, it is probable that Asian American university students are more likely to report career decision-making problems and to perceive them as more serious than other categories of problems (Mau \& Jepsen, 1990).

It is notable that university students reported considerably fewer difficulties in career decision making than high school students, regardless of race-ethnicity. University students as a whole may have become more mature in their approach to career decision making. This finding suggests evidence that the measure of career decision-making difficulty may be developmentally appropriate. However, further studies using longitudinal data would be needed to examine this issue.

\section{Implications}

The importance of process variables cannot be overemphasized in career decision making. Gati, Saka, and Krausz (2001) have described various counseling interventions for specific types of difficulties. For example, to help individuals dealing with external conflicts, counselors could encourage them to consider the importance of the "significant others" involved; to frame the conflicts in terms of occupational aspects rather than alternatives; or to convince significant others by discussing aspects. Studies ( Gati et al., 2001; Mau \& Jepsen, 1992) have shown the effectiveness of computer-assisted career guidance systems (CACGSs) in the reduction of career decision-making difficulties, especially as they relate to lack of information. Individual clients with specific decision-making difficulties can be directed to the most relevant CACGS, related Internet resources, or face-to-face counseling.

In general, regardless of race-ethnicity and educational levels, students in this study rated greater difficulties before the decision-making process than during the process. The difference in readiness (before the process) between high school students and university students was much smaller than it was in lack of information and inconsistent information (both during the process). This finding suggests that more counseling help may be needed to get students ready for career decision making. Increasing attention has been given to the assessment of decision-making readiness (Sampson, Peterson, Reardon, \& Lenz, 2000). The CDDQ may offer a valuable instrument for such assessment. For example, individuals assessed as low in readiness may benefit from individual case-managed services with a relatively longterm intervention; brief staff-assisted service might be appropriate for an individual assessed as 
moderately ready; and individuals with high readiness could use self-help services with little or no assistance from counselors.

Counselors need to recognize the cultural differences in the difficulties of career decision-making tasks. The causes of decision-making difficulties may differ among cultural groups and, therefore, may require different counseling approaches. For example, a person who is assessed as being indecisive could, in fact, be "normal" within his or her own cultural environment. Leong (1991) found that Chinese American college students preferred a dependent style. It is culturally insensitive to prejudge an individual as immature when he or she seeks approval from parents for his or her career choices. For individuals from collective cultural back-grounds, involving parents, family members, a godfather, and so on, in the decision-making process may be appropriate (Brown, 2003).

It is reasonable to assume that individuals from a collective cultural background may be more likely to experience external conflicts. External conflicts arise when the deliberating individual decides to take a certain factor into account or choose a certain occupation whereas his or her significant other(s) prefers otherwise. As predicted in the present study, Asian students were much more likely to experience external conflicts than other groups. Counselors working with this cultural group need to pay more attention to the kind of conflicts they are struggling with and use culturally appropriate techniques to help them resolve those conflicts.

Future studies should extend exploration of these observations. A logical extension of this study would include the use of a larger representative sample from each of the ethnic minority groups and the use of error-partitioning techniques such as GENOVAs or IRTs that permit a direct examination of bias due to cultural and contextual factors (Blustein \& Ellis, 2000). Future studies should also be conducted to examine the influence of specific factors (e.g., cultural identity development, value orientation, decisionmaking styles) on both the content and process of career decision making. Further research will help determine the applicability of career assessment to cultural minorities.

\section{References}

Bellah, R. N., Madsen, R., Sullivan, W. M., Swidler, A., \& Tipton, S. M. (1985). Habits of the heart: Individualism and commitment in American life. Berkeley: University of California Press.

Blustein, D. L., \& Ellis, M. V. (2000). The cultural context of career assessment. Journal of Career Assessment, 8, 379-390.

Brown, D. (2003). Career information, career counseling, and career development (8th ed.). Boston: Allyn \& Bacon.

Fouad, N. A., \& Zao, K. E. (2000). Meeting and revolution: Future trends in vocational assessment. Journal of Career Assessment, 8, 403-409.

Gati, I., Krausz, M., \& Osipow, S. H. (1996). A taxonomy of difficulties in career decision-making. Journal of Counseling Psychology, 43, 510-526.

Gati, I., Osipow, S. H., Krausz, M., \& Saka, N. (2000). Validity of the Career Decision-Making Difficulties Questionnaire: Counselee versus career counselor perceptions. Journal of Vocational Behavior, $56,99-113$.

Gati, I., \& Saka, N. (2001). High school students' career-related decision-making difficulties. Journal of Counseling \& Development, 79, 331-340.

Gati, I., Saka, N., \& Krausz, M. (2001). "Should I use a computer-assisted career guidance system?" It depends on where your career decision-making difficulties lie. British Journal of Guidance and Counselling, 29, 301-321.

Hofsrede, G. (1980). Culture's consequences: International differences in work-related values. Beverly Hills, CA: Sage.

Hui, C. H., \& Triandis, H. C. (1986). Individualism-collectivism: A study of cross-cultural researchers. Journal of Cross-Cultural Psychology, 17, 225-248. 
Hui, C. H., \& Villareal, M. J. (1989). Individualism-collectivism and psychological needs: Their relationships in two cultures. Journal of Cross-Cultural Psychology, 20, 310-323.

Lent, W. L., Brown, S. D., \& Hackett, G. (1994). Toward a unifying social cognitive theory of career and academic interest, choice, and performance. Journal of Vocational Behavior, 45, 79-122.

Leong, F. T. (1991). Career development attributes and occupational values of Asian American and European American college students. The Career Development Quarterly, 39, 221-230.

Leong, F. T., \& Hartung, P. J. (2000). Cross-cultural career assessment: Review and prospects for the new millennium. Journal of Career Assessment, 8, 391-401.

Leong, F. T., \& Leung, S. A. (1994). Career assessment with Asian-Americans. Journal of Career Assessment, 2, 240-257.

Leung, S. A., \& Hou, Z. (2002, August). Career decision-making difficulties of high school students in Hong Kong and Beijing. Paper presented at the 110th Annual Convention of the American Psychological Association, Chicago.

Luzzo, D. A., \& McWhirter, E. H. (2001). Sex and ethnicity differences in the perception of educational and career-related barriers and level of coping efficacy. Journal of Counseling \& Development, 79, 6167.

Mau, W. C. (2000). Cultural differences in career decision-making styles and self-efficacy. Journal of Vocational Behavior, 53, 365-378.

Mau, W. C. (2001). Assessing career decision-making difficulties: A cross-cultural study. Journal of Career Assessment, 9, 353-364.

Mau, W. C., \& Jepsen, D. A. (1990). Help-seeking perceptions and behaviors: A comparison of Chinese and American graduate students. Journal of Multicultural Counseling and Development, 18, 94-104.

Mau, W. C., \& Jepsen, D. A. (1992). Effects of computer-assisted instruction in using formal decisionmaking strategies to choose a college major. Journal of Counseling Psychology, 39, 185-192.

Osipow, S. H., \& Gati, I. (1998). Construct and concurrent validity of the Career Decision-Making Difficulties Questionnaire. Journal of Career Assessment, 6, 347-364.

Sampson, J.P., Peterson, G. W., Reardon, R. C., \& Lenz, J. G. (2000). Using readiness assessment to improve career services: A cognitive information-processing approach. The Career Development Quarterly, 49, 146-174. 